\title{
Endogenous Sex Hormone Levels and Breast Cancer Risk
}

\author{
Lisa Begg, Lewis H. Kuller, James P. Gutai, Arlene G. Caggiula, \\ Norman Wolmark, and Charles G. Watson
}

Department of Epidemiology, Graduate School of Public Health (L.B., L.H.K., A.G.C.), Montefiore Hospital, Department of Surgery, School of Medicine, (N.W.), Presbyterian University Hospital, Department of Surgery, School of Medicine (C.G.W.), University of Pittsburgh, Pittsburgh, and Children's Hospital of Michigan, Division of Endocrinology, Detroit (J.P.G.)

Sex-steroid hormones are a major determinant of the risk of breast cancer. We evaluated the relationship between obesity and endogenous estrogen levels in 79 healthy, postmenopausal women. Thirty-nine of the women were siblings of patients with postmenopausal-onset breast cancer; the remaining women were agematched $( \pm 10 \mathrm{yr})$ controls. Our hypothesis was that the siblings of the breast cancer patients would weigh more and that this excess weight would lead to higher serum estrone levels. The choice of unaffected family members of breast cancer patients reduces the concern that results may have been influenced by the cancer rather than antecedent to its development. Our findings demonstrated a statistically significant excess estrone level in the siblings compared to the controls (58.9 vs $47.8 \mathrm{pg} / \mathrm{ml}, \mathrm{P}=0.005$ ). The siblings weighed $4.3 \mathrm{~kg}$ more than the controls. Matched pairs analysis (sibling-control), adjusting for weight, also showed significant differences in serum estrone levels. These differences were observed despite comparability in dietary intake, medication use, and personal medical history. These findings represent the first time that higher estrogen levels have been measured in siblings of postmenopausal breast cancer patients. This observation may represent an important link in our understanding of the relationship between genetic and environmental risk factors of breast cancer. One approach to subsequent genetic studies of breast cancer may be to focus on the possible biological determinants such as sex-steroid hormone level receptors, oncogenes, and gene products and not on the "familial aggregation" of breast cancer.

Key words: endogenous estrogens, obesity, breast cancer, etiology, genetics

Received for publication February 16, 1987; revision accepted April 16, 1987.

Address reprint requests to Dr. Lisa Begg, Department of Epidemiology, Graduate School of Public Health, 507 Parran Hall, University of Pittsburgh, Pittsburgh, PA 15261.

(C) 1987 Alan R. Liss, Inc. 


\section{INTRODUCTION}

The etiology of breast cancer is acknowledged to be multifactorial [MacMahon et al, 1973; Kelsey, 1979]. Some of the risk factors are classified as environmentally related while others are considered to have a genetic predisposition [deWaard, 1973].

Three of the most commonly cited risk factors are fat intake, obesity, and endogenous estrogens and other hormones [Kelsey, 1979]. The familial aggregation of cases has been recognized since the late 1800s [Miller, 1979]. Virtually all reports confirm this finding regardless of their country of origin or study design [Lynch, 1980]. More recent reports further suggest that familial aggregation may represent common environmental exposures such as dietary consumption patterns [Armstrong and Doll, 1982] in addition to a genetic component. Obesity has been identified as a risk factor for postmenopausal-onset breast cancer [Kirschner et al, 1981]. Recent reports suggest a strong genetic component to obesity [Stunkard et al, 1986].

The role of endogenous estrogens in breast carcinogenesis has been less extensively studied [Kelsey, 1979; Henderson et al, 1982]. There are experimental, epidemiologic, and clinical data that suggest that endogenous estrogens play a crucial role. Experimentally, estrogens are known to be cocarcinogens in rodents [Kirschner, 1977]. Clinically, ovarian ablation influences the course of breast cancer [McGuire, 1981]. Artificial menopause by surgery or radiation substantially reduces the risk of breast cancer. Furthermore, the reduction of risk is greater the younger the age at time of artificial menopause [Feinleib, 1968]. There is some evidence that exogenous estrogen use may increase the risk of breast cancer especially among long-term users and sisters of breast cancer patients [Brinton, 1984].

Based on epidemiologic studies, hormone-mediated factors are strongly suspected of being related to breast cancer because increased risk is associated with events such as menarche, menopause, and first pregnancy [Pike et al, 1981]. Several endocrine glands and their hormones appear to influence the development and functioning of breast tissue. Moreover, breast cancer does not appear prior to menarche or in conditions associated with ovarian dysgenesis. It is also rare in males. The metabolic effects of estrogen are determined by the presence of specific receptors on target cells that bind and retain estrogen [Stanford, et al., 1986]. The epidemiology of estrogen receptors and breast cancer has recently been reviewed by Stanford. Estrogen probably effects target cells at the level of gene expression and subsequent protein synthesis. Multiple genetic abnormalities of estrogen metabolism are, therefore, possible from increased production of estrogen in response to environmental studies to receptor abnormalities to oncogene stimulation to abnormal gene product. This paper focuses on one component and tests the hypothesis that sisters of postmenopausal breast cancer patient have increased sex-steroid hormone levels, estrone, and estradiol. The approach is different from that of recent genetic studies, [Williams, 1984; King, 1984; Ottman, et al, 1986] that have focused on multiple case families, primarily young premenopausal women with very high risks within family that may be linked to a specific cellular genetic abnormality. The majority of breast cancer cases occur among postmenopausal women in which the familial association is usually of a much lower relative risk [Kelsey, 1979].

Estrogens have been characterized as being necessary but not sufficient for the development of breast cancer [Siiteri, 1980]. Others suggest an indirect role for the 
estrogens, since they create a permissive or promotional environment for neoplastic transformation and growth [Brennan, 1977; Miller and Bulbrook, 1980].

Most of the studies on endogenous estrogens have reported urinary or serum estrogen levels in breast cancer patients. Only one study has shown a significant relationship between total estradiol, nonprotein-based estradiol, and breast cancer [Moore et al, 1982]. Part of the explanation may be owing to the difficulty in quantifying these hormones especially in premenopausal women. Despite the lack of significant results, the serum estrogen levels tended to be higher in the breast cancer cases although still within normal ranges [Cole et al, 1978; Drafta et al, 1980; McFayden et al, 1976].

The measurement of the urinary metabolites is not as appealing an approach. The estriol hypothesis of breast cancer risk based on urinary measurements has lost support because estriol has been found to be carcinogenic in animals and the amount of estriol compared to the other two estrogens is very small [Kelsey, 1979]. Metabolic studies have also questioned the role of estriol in the development of breast cancer. Urinary studies are difficult to conduct because many factors influence excretion patterns such as other illnesses, medications, and nutrition [Kirschner, 1977].

The evidence is strong that increased blood levels of endogenous estrogens in postmenopausal women may be a key risk factor for breast cancer in postmenopausal women. The other risk factors such as family history, diet, alcohol, and obesity may act primarily by influencing the sex steroid hormone levels. A possible hypothesis is that family members are at increased risk of breast cancer because of different hormonal responses to environmentally related risk factors.

\section{METHODS}

Eighty ostensibly healthy women, $49-85 \mathrm{yr}$, were recruited for study between October 1983 and May 1984. All women were caucasian. Forty of these women were sisters of women with histologically confirmed breast cancer, postmenopausal onset. The remaining women, matched individually on age $( \pm 10 \mathrm{yr})$, served as healthy controls. The choice of unaffected family members of breast cancer patient reduces the concern that results may have been influenced by the cancer rather than antecedent to its development. Seventy-five percent of the controls were recruited through friendship networks, the remainder through community or extended family sources. Biochemical confirmation of postmenopausal status for each participant was determined by follicle-stimulating hormone (FSH) levels in excess of $30 \mathrm{MIU} / \mathrm{dl}$ [Nordin et al, 1981]. There were, therefore, 39 pairs available for matched pair analysis.

After obtaining written informed consent, data were obtained through home interviews. All home interviews were conducted between 8 am and 11 am. Interviewer-administered questionnaires on reproductive, personal, and family medical histories, demographic information, and dietary intake were obtained. Personal medical histories included questions on current medication use and within the 6 mo prior to interview. Dietary intake was obtained through the use of a continuous 3-day food record. The interviewer instructed each participant in the recording of dietary intake and documented each record after it was returned. A registered dietician, blinded to the study status of the participant, entered all food record data via a computerized data bank, which utilized the Agricultural Handbook, Number 456 [Agricultural Research Service, 1975]. A report on the dietary intake oi these women is under 
review [Begg et al, 1987]. Anthropometric measurements were obtained using a standardized protocol [National Center for Health Statistics, 1978]. A fasting blood specimen was obtained for lipoprotein and sex steroid hormone determinations. Each blood specimen was allowed to clot at room temperature and then maintained on ice until processed in the laboratory. All serum was stored in a minus $70^{\circ} \mathrm{C}$ freezer in 4$\mathrm{ml}$ aliquots until the analyses were performed. The blood specimens for the sisters and their matched controls were obtained within a few days of one another. These specimens were stored in the same Ultrafreezer and analyzed within the same batches. Lipid and sex-hormone analysis were run blindly, ie, the technicians were not aware of the study status of the participants. Lipoprotein levels were analyzed in a central laboratory that was monitored by the US Centers for Disease Control Standardization program.

Serum estrone and estradiol concentrations were measured on the same serum sample following extraction, LH-20 Sephadex column chromatography and radioimmunoassay (RIA) using a specific antibody [Radfar et al, 1976; Korenman et al, 1974; Cauley et al, 1986a]. The column chromatography gives complete separation between estrone, estradiol, and estriol. A small amount of radioactivity was added to each sample prior to extraction. The recovery of the radioactivity was used to adjust each sample for procedural losses during extraction and subsequent chromatography. The concentration of steroid in the appropriate column eluate was measured in triplicate. If there was greater than $10 \%$ variation of the triplicates, a repeat extraction, chromatography and RIA was performed. The estrone antibody was purchased from Endocrine Sciences and the estradiol antibody obtained from Dr. Gordon Niswender. Three portions of the estrone column eluate were used in the RIA. Since the concentration of estradiol was much lower, only a single portion of the estradiol column eluate was used in the RIA. Each assay set contained duplicates of the quality control plasma. The within (intra) assay coefficient of variation of estrone and estradiol was $12 \%$ and $11 \%$. The between assay variation was $6 \%$ and $16 \%$, respectively.

Serum testosterone and androstenedione were measured on the same serum sample following extraction, LH-20 Sephadex column chromatography and (RIA) using a specific antibody [deLacerda et al, 1973; Carr et al, 1971; Gutai et al, 1981]. The column chromatography gave complete separation between testosterone, androstenedione, and dihydrotestosterone. Each assay set included duplicate samples of the quality control pool. The within (intra) assay coefficient of variation for testosterone and androstenedione was $9 \%$ and $11 \%$ respectively. Blood used to prepare a large quality control pool was obtained from healthy volunteers and handled in the same way as the study samples. At the conclusion of the study, the results of the determinations of the quality control serum were reviewed. For all of the hormones measured there was no significant difference in the quality control serum at the beginning or conclusion of the study. This would indicate that there was no significant effect of prolonged freezing on the concentration of the hormones. Additionally, the results of the quality control samples were divided into four time periods and there was no significant difference between the means of the four time periods and the mean of the entire study set.

In addition, ten blinded replicates from study participants were used to evaluate interassay variability. The variation within individuals for the ten "dummy" results was $12 \%$ (SE 1.5) of the original results.

The evaluation of biological variability for serum estrone levels in postmenopausal women from this laboratory found the interindividual variability to be five 
times greater than the laboratory variability [Cauley et al, 1986a]. More importantly, there were neither significant biologic variability nor significant interaction over the four week period. These results suggest that a single measurement for estrone is reliable in characterizing a postmenopausal women for epidemiologic research at a single point in time.

Data analysis included descriptive statistics, univariate and multivariate statistical packages developed by SPSS [Hull and Nie, 1981] and BMDP [Dixon, 1985].

\section{RESULTS \\ Group Data}

The distribution by group of age, height, weight, body mass index, serum estrone, estradiol, and lipoproteins for the 39 siblings and 40 controls are shown in Table I. Fewer siblings were married or were ever pregnant. A greater proportion of siblings reported ever having smoked cigarettes compared with the controls. For the subset of women who reported a natural menopause $(\mathrm{N}=50)$, the mean ages were $49.2 \pm 4.9$ for the siblings and $48.3 \pm 4.0$ for the controls. Mean years since natural menopause was $13.1 \mathrm{yr}$ and $13.3 \mathrm{yr}$ for the siblings and controls, respectively. An additional 29 participants underwent a surgical menopause. For the 13 siblings, the mean age was $45.5 \mathrm{yr}$ and for the 16 controls $45.6 \mathrm{yr}$. Mean years since surgical menopause for the siblings was $17.9 \mathrm{yr}$ and for the controls $16.8 \mathrm{yr}$. Body mass index (BMI) was calculated using weight divided by height squared. Mean weight was 4.3 $\mathrm{kg}$ (or $9.5 \mathrm{lbs}$ ) greater in the siblings compared to the controls. Median weight was also higher in the siblings versus the controls $(69.9$ vs $61.5 \mathrm{~kg})$. Mean height was comparable so the higher BMI observed in the siblings was owing to their excess weight levels compared to the controls.

Both total cholesterol and high-density lipoprotein cholesterol levels were nonsignificantly lower in the siblings compared to the controls (Table I).

Serum estrone, the predominant estrogen in postmenopausal-aged women, was found to be significantly higher, $58.9 \mathrm{vs} 47.8 \mathrm{pg} / \mathrm{ml}$, in the siblings compared to the controls (Student's t test, one-tail, $\mathrm{P}=0.005)$. For the subset of women $(\mathrm{N}=59)$ for whom there was sufficient serum for estradiol measurements, the siblings had significantly higher levels than the controls, 7.9 vs $5.4 \mathrm{pg} / \mathrm{ml}, \mathrm{P}=0.04$.

The frequency distribution for serum estrone by group reveals that at a level of less than $50 \mathrm{pg} / \mathrm{ml}$ of estrone, fewer siblings (45\% vs $62.5 \%$ ) are represented; between $50-69 \mathrm{pg} / \mathrm{ml}$ of estrone, the distributions are equal and above $70 \mathrm{pg} / \mathrm{ml}$ of estrone $23 \%$ of the siblings are represented compared to $5 \%$ of the controls. The median serum estrone level of the siblings was $57.0 \mathrm{pg} / \mathrm{ml}$ and $45.6 \mathrm{pg} / \mathrm{ml}$ for the controls.

The paired serum estrone differences were computed by subtracting the absolute estrone value of the control from the estrone value of her matched sibling. The range of differences went from a -52.9 to +73.0 . There were eight pairs with negativeestrone difference (sibling - control, Table II). There were 30 positive-estrone difference pairs and one pair with equivalent estrone levels so that the paired difference was less than $1 \mathrm{pg}$. Eighteen of the thirty positive-estrone difference pairs recorded less than a $20 \mathrm{pg}$ difference. The remaining 12 paired differences ranged from 21.2 to $73.0 \mathrm{pg}$. The mean relative difference was 10.8 with a standard error of 4.1 $(\mathrm{P}=0.005)$. 


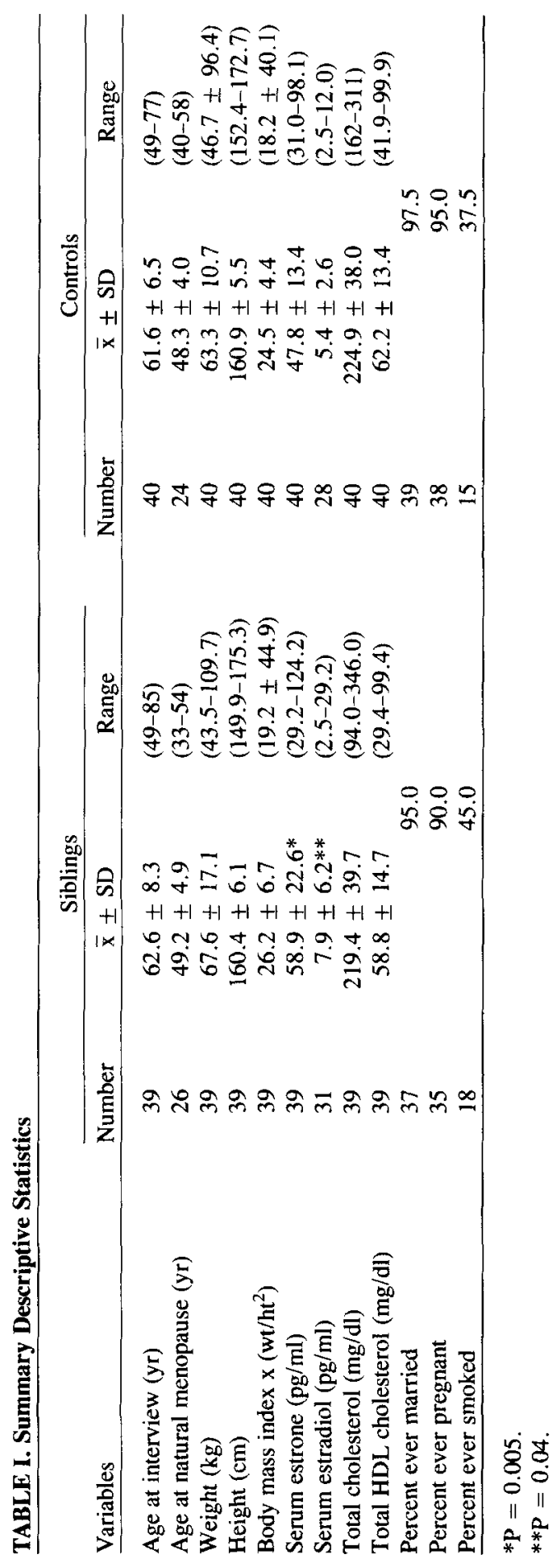


TABLE II. Distribution of Paired Serum Estrone Differences

\begin{tabular}{lc}
$\begin{array}{l}\text { Interval difference } \\
\text { sibling-control } \\
\text { estrone }(\mathrm{pg} / \mathrm{ml})\end{array}$ & $\begin{array}{c}\text { Number of sibling- } \\
\text { control pairs }\end{array}$ \\
\hline$\leqslant-11$ & 5 \\
$-10--1$ & 3 \\
$0-9$ & 9 \\
$10-19$ & 10 \\
$20-29$ & 6 \\
$30-39$ & 3 \\
$\geqslant 40$ & 3 \\
\hline Mean relative difference (sibling-control) & 10.8 \\
Standard error & 4.1 \\
\hline
\end{tabular}

TABLE III. Univariate Correlation Coefficents of Serum Estrone With Selected Variables by Group*

\begin{tabular}{lrcrrr} 
& \multicolumn{2}{c}{ Sibling } & & \multicolumn{2}{c}{ Control } \\
\cline { 2 - 3 } \cline { 5 - 5 } Selected variables & $\mathrm{r}$ & $\mathrm{P}$ & & $\mathrm{r}$ & $\mathrm{P}$ \\
\hline Weight & 0.39 & 0.007 & & 0.57 & 0.00 \\
Body mass index & 0.34 & 0.01 & 0.55 & 0.00 \\
Total cholesterol & -0.24 & 0.07 & 0.00 & 0.49 \\
LDL cholesterol & -0.33 & 0.02 & -0.10 & 0.27 \\
Total HDL cholesterol & -0.16 & 0.15 & -0.05 & 0.39 \\
HDL-2 cholesterol & -0.13 & 0.21 & 0.00 & 0.49 \\
HDL-3 cholesterol & -0.12 & 0.22 & 0.03 & 0.42 \\
Total triglycerides & 0.13 & 0.20 & 0.14 & 0.19 \\
\hline
\end{tabular}

*HDL $=$ high density lipoprotein; LDL, low density lipoprotein; body mass index $=$ weight/height ${ }^{2}$.

Statistically significant associations were observed for weight and Body Mass Index (BMI) in each group and serum estrone levels. These correlations were higher in the control group compared to the siblings. There was a stronger inverse relationship between low-density lipoprotein cholesterol and serum estrone in the sibling group (Table III). The relationship between high-density lipoprotein cholesterol levels and serum estrone was not significant.

To evaluate further the determinants of serum estrone, multiple regression analyses were performed using both the absolute serum estrone levels and the logarithmic-transformed values. The results were similar.

The independent variables used were age, study status (sibling or control), current smoker (yes/no), and current weight $(\mathrm{kg})$. Current weight, rather than BMI, was used because height was comparable in each group, making weight a better direct measure of ponderosity. Both study status and current weight were found to be statistically significant. In both analyses, current weight was highly significant, with a $P$ value of less than 0.0001 and for study status, $P=0.03$. The regression coefficient for study status was negative because serum estrone levels were higher in siblings than controls (Table IV). The results were similar if BMI was used instead of current weight. 
TABLE IV. Multiple Regression Analysis of Determinants of Serum Estrone Levels ( $N=79)$

\begin{tabular}{lcccc} 
& Coefficient & SE & $\begin{array}{c}\text { Standard regression } \\
\text { coefficient }\end{array}$ & P (2 tail) \\
\hline Age & -0.02222 & 0.27639 & -0.008 & 0.9361 \\
Study status ${ }^{\mathrm{a}}$ & -8.44069 & 3.91967 & -0.219 & 0.0345 \\
Current smoker $_{\text {Current weight }}$ & 3.15103 & 5.02337 & 0.067 & 0.5324 \\
lut & 0.59208 & 0.14010 & 0.440 & 0.0001 \\
\hline
\end{tabular}

${ }^{a}$ Study status defined as siblings or controls.

TABLE V. Summary Distribution of Paired Weight and Estrone Differences

\begin{tabular}{lccc}
\hline $\begin{array}{l}\text { Paired weight } \\
\text { difference }\end{array}$ & $\begin{array}{c}\text { Number } \\
\text { of weight } \\
\text { categories }\end{array}$ & $\begin{array}{c}\text { Sibling estrone levels } \\
\text { greater than control } \\
\text { levels (positive-estrone } \\
\text { differences) }\end{array}$ & Percent \\
\hline Sibling > control & 21 & 20 & 95.3 \\
Sibling $\cong$ control & 3 & 2 & 66.6 \\
Sibling < control & 15 & 8 & 60.0 \\
\hline Total pairs & 39 & 30 & 76.9 \\
\hline
\end{tabular}

\section{Matched Pairs Analysis}

Body weight is a known determinant of serum estrone levels [Siiteri et al, 1976; Judd et al, 1976]. Matched pairs analyses were performed to adjust for weight so that the nonweight mediated influence could be better quantified. The adjustment was necessary because weight, which is a continuous variable, was discordant within the pairs. Thirty-nine pairs were available for the three methods of matched pairs analysis: 1) nonparametric ranking of the paired differences, 2) analysis of residual estrone levels, and 3) calculations of weight-adjusted serum estrone differences. There were no differences in height between cases and controls. Weight differences were, therefore, used rather than BMI.

\section{Nonparametric Ranking}

The distribution of paired estrone differences in relationship to paired weight differences was created by first ranking the individual paired differences for weight from the most extreme negative values where the sibling was lighter than her matched control to the most positive value when the sibling registered a much higher weight than her control.

There were 15 negative-weight pairs (sibling - control) and twenty one positiveweight pairs (Table V). Three pairs in which the sibling and her control were essentially equal weights, registered a paired-weight difference of less than $1 \mathrm{~kg}$. Using a ranking of the paired weight differences, there were 8 negative-estrone pairs and 30 positive-estrone pairs. One pair had equivalent estrone levels.

When the two distributions are combined employing the ranking based on the paired weight differences, 8 of the 15 negative-weight pairs exhibit positive-estrone differences. Twenty of the twenty one positive-weight pairs exhibited positive-estrone differences. Two of the three equal-weight pairs showed positive-estrone differences and one showed a negative-estrone difference. Thus compared with the match but controlling for weight, 8 of the 15 siblings still had higher estrone levels even in situations where the control weighed more than the sibling. 


\section{Analysis of Residual Estrone Levels}

For the second method of paired analysis, scatter plots of the absolute estrone and weight levels were obtained for all 79 participants and for the 40 controls alone. The two approaches were used to minimize the possible bias of calculating residual estrone values based solely on the control group. The distribution of paired residual estrone levels using the absolute estrone levels as compared to the estimated estrone levels for her specific weight in both equations revealed very similar results (Table VI). Using the controls only equation, there were 15 negative-estrone difference pairs, where the sibling had a lower residual estrone level than her control. There were 14 negative-estrone difference pairs with the $\mathrm{N}=79$ equation. A matched paired difference $t$ test was performed comparing the residual estrone value in case versus matched control. The difference was statistically significant, $P=0.02$ level. The Wilcoxan matched pair signed rank test (one-tail) was also found to be statistically significant using both the $\mathrm{N}=79$ equation $(\mathrm{P}=0.009)$ and the $\mathrm{N}=40$ equation $(\mathrm{P}=0.002)$.

\section{Weight-Adjusted Serum Estrone Difference}

The third method employed to adjust the serum estrone levels by weight was completed by using the actual serum estrone level $(\mathrm{pg} / \mathrm{ml})$, divided by the individual weight (in $\mathrm{kg}$ ). Paired estrone differences, now adjusted by weight, were obtained for each of the sibling-control pairs. The distribution of these paired estrone differences was similar to Table V, shown earlier, which calculated the absolute estrone differences using a weight ranking. The weight-adjusted calculation resulted in a downward shift in the paired values. Fifteen of thirty nine pairs were estrone negative from the residual analysis (Table VI) compared to $8 / 39$ pairs in Table V where no weight adjustment was made.

Although the principle sex-steroid hormone in postmenopausal women is estrone, the levels of estradiol may be important. The levels of estradiol were significantly higher in the siblings, $7.9 \mathrm{pg} / \mathrm{ml}$ as compared to the $5.4 \mathrm{pg} / \mathrm{ml}$ for the controls, $\mathrm{P}=0.04$ (Table I). There was, unfortunately, not enough serum available for the measures of estradiol in all subjects and the matched pairs could not be done. The estradiol levels were highly correlated with estrone levels and also with body weight and body mass index (Table VII). This was true for both cases and controls.

Estrone is not bound to sex-hormone binding globulin, while estradiol is bound [Siiteri et al, 1982]. The amount of free estradiol in postmenopausal women is

TABLE VI. Summary Table for Analysis of Residual Estrone Levels

\begin{tabular}{|c|c|c|}
\hline & $\mathrm{N}=?$ & $\times X$ \\
\hline & Sibling $>$ control & Sibling $<$ control \\
\hline Paired & & \\
\hline Estrone & 25 & 14 \\
\hline Differences & & \\
\hline & $\mathrm{N}=4$ & $\times x$ \\
\hline & Sibling $>$ control & Sibling $<$ control \\
\hline Paired & & \\
\hline Estrone & 24 & 15 \\
\hline Differences & & \\
\hline
\end{tabular}


TABLE VII. Pearson Correlations for Serum Estradiol With Selected Variables

\begin{tabular}{lccccc} 
& \multicolumn{2}{c}{ Sibs $(\mathrm{N}=31)$} & & \multicolumn{2}{c}{ Controls $(\mathrm{N}=28)$} \\
\cline { 2 - 3 } \cline { 6 - 7 } Variables & $\mathrm{r}$ & $\mathrm{P}$ & & $\mathrm{r}$ & $\mathrm{P}$ \\
\hline Serum estrone & 0.57 & 0.00 & 0.40 & 0.01 \\
Weight & 0.54 & 0.001 & 0.35 & 0.03 \\
BMI $^{\mathrm{a}}$ & 0.49 & 0.002 & 0.35 & 0.03 \\
\hline
\end{tabular}

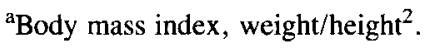

extremely low, probably less than $1 \mathrm{pg} / \mathrm{ml}$ [Siiteri et al, 1986] and cannot be reliably measured in these postmenopausal women. Even if the free estradiol is a much more potent estrogen than estrone it is probably unlikley that the less than 1 pg levels as compared to the almost $50 \mathrm{pg}$ levels of estrone would contribute substantially to the total estrogen effect.

Serum testosterone and androstenedione were also measured. The androstenedione levels were 111.11 ng/dl in the 35 siblings (SD 41.5) and 92.83 (SD 38.6) in 29 controls $(P=0.07)$. The androstenedione levels were significantly correlated with the estrone levels for both the siblings and controls.

The mean testosterone levels were $54.9 \mathrm{ng} / \mathrm{dl}$ (SD 39.9) in 35 siblings and 38.55 (SD 24.9) for 29 controls $(P=0.05)$. The testosterone levels were highly correlated with estradiol levels for both siblings and controls but not with the estrone levels. The "free" testosterone levels were not measured.

\section{DISCUSSION}

Excess body weight is known to be a risk factor for breast cancer [Kelsey, 1979; Krischner et al, 1982; Paffenbarger et al, 1980], and as expected the siblings weighed more than their matched controls. Using group statistics, the mean body weight of the siblings are $4.3 \mathrm{~kg}$ more than the control group. The siblings also had a higher median weight than the controls. On matched-pairs analysis, 20 of 21 sibling-control pairs recorded excess weight differences (Table II). Thirty of the 39 sibling-control pairs have higher serum estrone levels (Table V). When the two distributions are combined, adjusting for weight, 20/21 excess weight pairs also record higher estrone levels in siblings versus controls (Table V). Some of the negative-weight pairs (sibling weighs less than her control) have higher estrone levels in the siblings. We did further analysis to evaluate these individuals.

In Figure 1, the degree of obesity is compared with estrone levels. Based on current knowledge about estrogen metabolism, participants who fall within quadrants I and IV demonstrate the expected biological relationships. That is, women who are leaner should have lower estrone levels than more obese women. It is the women who fall within quadrants II and III who deviate from the expected biological relationships. From what we know about breast carcinogenesis, women in quadrant II are the most important to evaluate. These participants exhibit high estrone levels even though they are relatively lean. Seven of the ten participants in quadrant II are siblings of breast cancer patients. This finding lends further support to the hypothesis that the potential increased risk of breast cancer in postmenopausal siblings may be a function of their higher estrogen levels in response to environmental stimuli such as obesity, diet, and alcohol. 


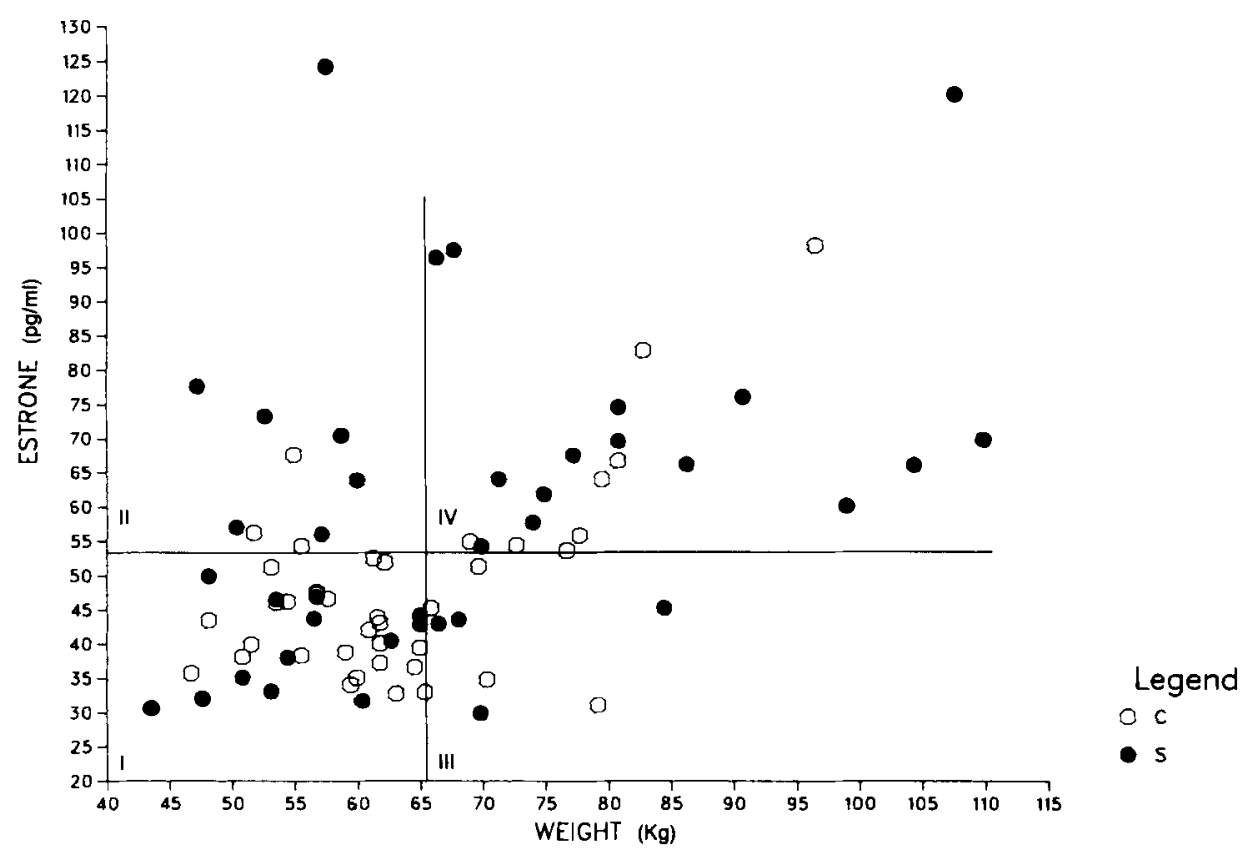

Fig. 1. Figure 1 shows serum estrone on the $\mathrm{Y}$ axis and body weight on the $\mathrm{X}$ axis. Individual values are shown for each sibling estrone-weight data point and each control estrone-weight data point. Quadrant I represents those participants who recorded low estrone and low weight. Quadrant II contains those women with high estrone but low body weight. Quadrant III represents participants with low estrone but high body weight and quadrant IV contains women who exhibit both high estrone and high body weight. Estrone $(\mathrm{pg} / \mathrm{ml})$, combined mean for siblings and controls $=53.35$; Weight $(\mathrm{kg})$, combined mean siblings and controls $=65.5 . \mathrm{s}=$ sibling; $\mathrm{c}=$ control.

The results of this study represent the first time that higher estrone and estradiol levels have been measured in siblings of postmenopausal breast cancer patients. Such an observation may represent an important link in our understanding of the relationship between genetic and environmental risk factors for breast cancer. The genetic component to breast cancer etiology may be a function of either higher estrogen levels in the sisters of breast cancer patients at similar environmental exposures or perhaps to the greater sensitivity of the breast tissue to these estrogen levels. Genetic factors are more important with earlier onset of breast cancer [King et al, 1985; Lynch, 1980; Knudson, 1973]. However, other investigators have documented a substantial genetic contribution to the onset of postmenopausal breast cancer [Ottman et al, 1983, Henderson et al, 1974; Burns et al, 1981; Hislop et al, 1986; Ottman, 1986].

These estrogen differences are even more impressive given the comparability of the women on a large number of factors that may influence endogenous hormone levels. The siblings and their matched controls are remarkably similar in their ethnicity, age, reproductive and medical histories, years of education, and social class. The reported dietary intake is also similar at least based on analysis of 3-day food records on a subset of 30 pairs. Prior and current medication use between the groups is comparable. Blinded replicates for the estrone analysis were included and laboratory variability was found to be minimal. In general, our estrone and estradiol results are within the range of recent reports in the literature [Jensen et al, 1985; Lesko et al, 1985]. 
Furthermore, our hormone results have remained comparable across multiple studies completed within the last 3 years [Cauley et al., 1986a,b]. Studies performed on blood stored for many years showed significant differences in free estradiol concentrations between breast cancer cases and controls [Siiteri et al, 1981]. However, a subsequent study by the same group using blood stored for much shorter periods of time found no differences [Siiteri et al, 1986] and suggests that with prolonged storage there may have been a differential increase in the free estradiol in cases compared to controls. Our blood specimens (for both siblings and controls) were stored at $-70^{\circ} \mathrm{C}$ and measured within $1 \mathrm{yr}$.

A recent review of the relationship between estrogens and breast cancer note that in four of the five case-control studies, estradiol levels have been higher in the breast cancer cases than in the controls; one study in Holland did not confirm this relationship [Bulbrook et al, 1986].

This same report gave updated findings from a prospective study [Bulbrook et al, 1986]. There were only six postmenopausal cancer patients in the study and therefore it is very difficult, if not impossible, to evaluate the relationship between the hormone levels and subsequent risk of breast cancer. Overall, including predominantly the premenopausal patients, the free and albumin-bound estradiol levels appeared to be higher in the cases as compared to their matched controls. However, the entire study has only 16 cancer patients. The authors [Bulbrook et al, 1986] note that "it must be admitted that the role of protein binding of steroids and modulating their biological activity is not understood. Availability of protein bound hormones, varies from organ to organ and from species and species. At the moment the simple concept of non-protein bound estradiol and albumin bound estradiol are available for biological activity on normal and neoplastic breast tissue fits well with the limited data that has been obtained so far. Thus, the situation with regard to estrone, estradiol and free albumin bound estradiol in the postmenopausal women is far from clear."

In postmenopausal women, much of the estradiol is derived from estrone and clearly an almost 100 -fold difference between estrone and free estradiol in the blood suggests the possibility the estrone may be playing an important role in breast cancer risk in postmenopausal women. Estrone sulfate and other metabolities of estrogen may also be important in the etiology of breast cancer [Santner et al, 1984; Prost et al, 1984].

The estrone levels can clearly be shown to have physiological importance. A direct relationship has been demonstrated between endogenous estrone levels and bone density among postmenopausal women even after adjusting for body weight [Cauley et al, 1986a]. The estrone levels of the siblings of breast cancer patients are inversely related to low-density lipoprotein cholesterol. Thus, we think the postmenopausal levels of estrone are possibly related to three important diseases of postmenopausal women: osteoporosis, cardiovascular disease, and breast cancer risk. The major source of estrone in the postmenopausal women is from the aromatization of the adrenal steroid androstenedione, which occurs primarily in fat but also in muscle and other tissues. The androstenedione levels were higher in siblings than controls. Whether the increase in androstenedione is primarily responsible for higher estrone and estradiol levels in the siblings is unknown. As previously noted, the degree of obesity may also be partially influenced by genetic factors.

The results, although unique, are still based on a small sample. They do provide some evidence for a possible link between diet, obesity, hormones, genetic factors, 
and breast cancer. Obesity and possibly high fat or high caloric intake could result in elevated estrone and estradiol levels in postmenopausal women, primarily by increasing aromatization in adipose tissue, and possibly muscle tissue of androstenedione to estrone [Santen, 1982]. The degree of sensitivity to these evironmental stimuli may be at least partially genetically determined. The genotypic expression would therefore be the hormone levels. The relatively low order familial association of breast cancer is therefore probably due to the interrelationship of the environmental and the genetic determinants of the hormone levels and the response of breast tissue, the phenotypic expression.

Current and future prospective studies may delineate the specific relationships of endogenous hormone levels to breast cancer risk. These studies will need to measure both the hormone levels as well as metabolities such as estrone sulfate. The efficacy of specific dietary manipulations could then be evaluated in relationship to specific changes in hormonal parameters as well as in the risk of breast cancer. There is a continuing and important need to determine the specific effects of various environmental changes on endogenous hormone levels especially in both pre- and post-menopausal women. Such studies should evaluate the effects of specific dietary manipulations as well as caloric restriction and weight change. The combination of well controlled environmental manipulation and genetic studies in order to quantify changes in probable biochemical precursors of breast cancer offers the best approach to understanding the etiology of this disease.

\section{ACKNOWLEDGMENTS}

We are grateful to Mr. John Powell and Miss Beth Hauth for their laboratory analysis of the hormones and lipoproteins. We are indebted to Mrs. Peggy Krall and Miss Bett McLaughlin for their assistance in manuscript preparation. The cooperation of the breast cancer patients and their sisters and friends are also very much appreciated.

\section{REFERENCES}

Agricultural Research Serivce (1975), "Nutritive Values of American Foods in Common Units," Agricultural Handbook NO. 456, U.S. Department of Agriculture, Washington, DC.

Armstrong B, Doll R (1982): Diet. "Cancer Epidemiology and Prevention." Philadelphia: WB Saunders. Begg L, Caggiula A, Kuller LH et al (1987): Evaluation of dietary intake patterns in women who are at high risk for the development of breast cancer. Submitted to Am J Epid.

Brennan MJ (ed) (1977): Breast Cancer Research, Report Number 4, UIC Technical Report Series, Volume 27, Geneva.

Brinton, LA (1984): The relationship of exogenous estrogens to cancer risk. Cancer Detec Prev 7:159.

Bulbrook RD, Moore JW, Clark GMG, et al (1986): Relation between risk of breast cancer and biological availability of estradiol in the blood: Prospective study in guernsey. "Endocrinology of the Breast: Basic and Clinical Aspects." New York: New York Academy of Sciences, pp 378.

Burns PE, Lees AW, Hurlburt ME, et al (1981): Reproductive events and family history as risk factors for breast cancer in northern Alberta. CMA Journal 124(11):1451.

Carr RT, Mikhail G, Flickinger GL (1971): Column chromatography of steroids and sephadex LH-20. J Clin Endocrinol Metab 33:356.

Cauley JA, Gutai JP, Sandler RB, et al (1986a): The relationship of endogenous estrogen to bone density and bone area in normal postmenopausal women. Am J Epid 124(5):752.

Cauley JA, Gutai AP, Kuller LH, Sandler RB (1986b): Estrone and HDL-C in postmenopausal women. Circulation 74:II-332. 
Cole P, Cramer D, Yen S, et al (1978): Estrogen profiles of premenopausal women with breast cancer. Cancer Res 38:745.

deLacerda L, Kowarski A, Johanson AH, et al (1973): Integrated concentration and circadian variation of plasma testosterone in normal men. J Clin Endocrinol Metab 37:366.

deWaard F (1973): "Nurture and Nature in Cancer of the Breast and the endometrium: Host Environment Interactions in the Etiology of Cancer in Man." IARC, Lyon, France, pp 121-130.

Dixon WJ (ed). (1985): BMDP Statistical Software, 1985 Printing, University of California Press.

Drafta D, Schindler AE, Milcu StM, et al (1980): Plasma Hormones in pre- and postmenopausal breast cancer. J Steroid Biochem 13:793.

Feinleib M (1968): Breast cancer and artificial menopause: A cohort study. J Natl Cancer Inst 41:315329.

Gutai JP, laPorte R, Kuller LH, et al (1981): Plasma testosterone, high density lipoprotein, cholesterol, and other lipoprotein fractions. Am J Cardiol 48:897-901.

Henderson BE, Ross RK, Pike MC, et al (1982): Endogenous hormones as a major factor in human cancer. Cancer Res 42(8):3232.

Henderson B, Powell D, Rosario I, et al (1974): An epidemiologic study of breast cancer. JNCI 53(3):609.

Hislop TG, Coldman AJ, Elwood JM, et al (1986): Relationship between risk factors for breast cancer and hormonal status. Int J Epid 15(4):469-476.

Hull CH, Nie NH (1981): SPSS Update 7-9, New York: McGraw-Hill Book Company.

Jensen J, Christiansen C, Rodbro P (1985): Cigarette smoking, serum estrogens, and bone loss during hormone-replacement therapy early after menopause. N Engl J Med 313(16):973.

Judd HL, Lucas WE, Yen SSC (1976): Serum estradiol and estrone levels in postmenopausal women with and without endometrial cancer. J Clin Endocrinol Metab 43(2):272.

Kelsey JL (1979): A review of the epidemiology of human breast cancer. Epidemiol Rev 1:74.

King, MC, Lee GM, Spinner NB, Thomson G, Wrensch MR (1984): Genetic epidemiology. Ann Rev Publ Hlth 5:1-52.

King, MC, Elston, RC (1985): Genetic epidemiology of breast cancer: A comment on heterogeneity. Letters to the Editor, Gen Epidemiol 2:167.

Kirschner MA, Ertel N, Schneider G (1981): Obesity, hormones, and cancer. Cancer Res 41(9):3711.

Kirschner M (1977): The role of hormones in the etiology of human breast cancer. Cancer 39(6):2716.

Kirschner MA, Schneider G, Ertel N, et al (1982): Obesity, androgens, estrogens, and cancer Risk. Cancer Res 42:3281s.

Knudson AG (1973): Genetics in Cancer. "Achievements, Challenges and Prospects for the 1980's." Burchand JH, Oettgen HF (eds). New York: Grune and Stratton.

Korenman S, Stevens R, Carpenter LA, et al (1974): Estradiol Radioimmunoassay without chromatography. J Clin Endocrinol 39:718.

Lesko SM, Rosenberg L, Kaufman DW, et al (1985): Cigarette smoking and the risk of endometrial cancer. N Engl J Med 313(10):593.

Lynch HT (1980): Genetics, etiology, and human cancer. Prev Med 9(2): 231.

MacMahon B, Cole P, Brown J (1973): Etiology of human breast cancer; A review. J Natl Cancer Inst 50:21.

McFayden I, Prescott RJ, Forrest APM, et al (1976): Circulating hormone concentrations in women with breast Cancer. Lancet 1:1100.

McGuire WL (ed) (1981): "Breast Cancer." New York: Plenum, Vol. 4.

Miller AB (1979): Familial risk of cancer. Can Med Assoc J 121(5): 505.

Miller AB, Bulbrook RD (1980): The epidemiology and etiology of breast cancer. N Engl J Med 303(21): 1246.

Moore JW, Clark GMG, Bulbrook RD, et al (1982): Serum concentrations of total and non-proteinbound oestradiol in patients with breast cancer and in normal controls. Int J Cancer 29:17.

National Center for Health Statistics (1978): "Plan and Operation of the Hanes I Augmentation Survey of Adults 25-74 years," NIH Publications 78-1314, Hyattsville, MD.

Nordin BEC, et al (1981): Oestrogens, the menopause and the adrenopause. J Endocrinol 89:131.

Ottman R, Pike M, King MC, et al (1983): Practical guide for estimating risk for familial breast cancer. Lancet 2(8349):556.

Ottman R, Pike M, King MC, et al (1986): Familial breast cancer in a population-based series. Am J Epid 123(1): 15 . 
Paffenbarger RS, Kampert JB, Chang HG (1980): Characteristics that predict risk of breast cancer before and after the menopause. Am J Epidemiol 112(2):258.

Pike MC, Henderson BE, Casagrande JT (1981): The Epidemiology of Breast Cancer As It Related to Menarche, Pregnancy, and Menopause. "Banbury Report 8: Hormones and Breast Cancer." New York: Cold Springs Harbor.

Prost O, Turrel MO, Dahan N, et al (1984): Estrone and dehydroepiandrosterone sulfatase activities and plasma estrone sulfate levels in human breast carcinoma. Cancer Res 44:661-664.

Radfar N, Ansusingha K, Kenny F (1976): Circulating bound and free estradiol and estrone during normal growth and development. J Pediatr 89:719.

Santen RJ (1982): Introduction to the conference, aromatase: New perspectives for breast cancer. Cancer Res 42:32685.

Santner SJ, Feil PD, Santen RJ (1984); In Situ estrogen projection via the estrone sulfatase pathway in breast tumors: Relative importance versus the aromatase pathway. J Clin Endocrinol Metab $59: 29-33$

Siiteri PK (1980): Hormonal Basis of Risk Factors for Breast and Endometrial Cancer. "Progress in Cancer Research and Therapy: Hormones and Cancer New York: Raven Press, Vol. 14.

Siiteri P, Williams JE, Takaki NK (1976): Steroid abnormalities in endometrial and breast carcinoma: A unifying hypothesis. J Steroid Biochem 7:897.

Siiteri PK, Murai JT, Jammond GL, et al (1982): The serum transport of steroid hormones. Recent Prog Horm Res 38:457.

Siiteri PK, Simberg N, Murai J (1986): Estrogens and breast cancer. Ann. NY Acad Sci 464:100-105.

Siiteri PK, Hammond GL, Nisker JA (1981): Increased availability of serum estrogens in breast cancer: A new hypothesis. "Banbury Report 8: Hormones and Breast Cancer." New York: Cold Springs Harbor, pp 87-106.

Stanford JL, et al (1986): Estrogen receptors and breast cancer. Epid Reviews 8:42.

Stunkard, et al. (1986): A twin study of human obesity. JAMA 256(1):51.

Williams WE, Anderson DE (1984): Genetic epidemiology of breast cancer: Segregation analysis of 200 Danish pedigrees. Genet Epidemiol 1:7-20.

Williams WR, Anderson DE (1985): Genetic epidemiology of breast cancer: Further clarification and a response to King and Elston. Letters to the Editor, Genet Epidemiol.

Edited by D.C. Rao 